\title{
Management of hyperlipidaemia: guidelines of the British Hyperlipidaemia Association
}

\author{
D.J. Betteridge, P.M. Dodson', P.N. Durrington'2, E.A. Hughes ${ }^{3}$, M.F. Laker ${ }^{4}$, \\ D.P. Nicholls ${ }^{5}$, J.A.E. Rees 6 , C.A. Seymour ${ }^{7}$, G.R. Thompson ${ }^{8}$, A.F. Winder', \\ P.H. Winocour ${ }^{10}$ and R. Wray ${ }^{11}$
}

\begin{abstract}
Department of Medicine, University College London Medical School London; ${ }^{1}$ East Birmingham NHS Trust, Birmingham; ${ }^{2}$ Department of Medicine, University of Manchester; ${ }^{3}$ Sandwell District General Hospital, West Bromwich; ${ }^{4}$ Department of Medicine, University of Newcastle upon Tyne; ${ }^{5}$ Royal Victoria Hospital, Belfast; ${ }^{6}$ University Hospital of Wales, Cardiff; ${ }^{7}$ St George's Hospital Medical School, London; ${ }^{8}$ MRC Lipoprotein Team, Hammersmith Hospital, London; ${ }^{9}$ Department of Chemical Pathology, Royal Free NHS Trust and School of Medicine, London; ${ }^{10}$ Department of Medicine, University of Newcastle upon Tyne; and ${ }^{11}$ Department of Medicine, Hastings and Rother NHS Trust, UK
\end{abstract}

\section{Introduction}

There have been considerable advances in the understanding of plasma cholesterol and triglyceride metabolism and the lipoprotein particles which transport these important lipids. Epidemiological evidence linking plasma cholesterol to coronary heart disease (CHD) risk has been strengthened by the findings of the prospective part of the Multiple Risk Factor Intervention study. ${ }^{1}$ Furthermore, the study of populations with plasma cholesterol concentrations much below those seen in Western industrialized societies has pointed to a continuous gradient of CHD risk with increasing plasma cholesterol. ${ }^{2}$ The value of measurement of individual plasma lipoproteins in defining CHD risk more closely is now well established. Low density lipoprotein (LDL) cholesterol, is the major transporter of plasma cholesterol, and largely accounts for the relationship between total cholesterol and CHD. ${ }^{3}$ In contrast, high density lipoprotein (HDL), the other major cholesterolrich lipoprotein, is inversely related to CHD. ${ }^{4}$ The role of plasma triglyceride as an independent risk factor for CHD remains controversial, ${ }^{5}$ although there is no doubt of the atherogenicity of some triglyceride-rich lipoproteins, namely chylomicron remnant particles and intermediate density lipoproteins (IDL). Very high concentrations of plasma triglycerides, reflecting the accumulation of chylomicrons which transport exogenous fat from the intestine, are associated with risk of pancreatitis.

Correspondence: D.J. Betteridge, B.Sc., Ph.D., M.D., F.R.C.P., Department of Medicine, University College London Medical School, The Middlesex Hospital, Mortimer Street, London W1N 8AA, UK.

Accepted: 11 January 1993
Justification for attributing a causal role for LDL cholesterol in atherosclerosis has received considerable support from the outcome of both primary and secondary CHD prevention trials employing lipid modifying therapy. ${ }^{6,7}$ Although indirect evidence also points to the benefits of increasing plasma HDL concentrations and decreasing plasma triglyceride concentration, the bulk of evidence implicates LDL as the major atherogenic particle. Recent angiographic studies suggest that radical alteration of plasma lipids and lipoproteins by lifestyle, pharmacological and surgical measures can retard the progression of atherosclerotic lesions, delay the appearance of new lesions and in some patients lead to lesion regression $^{8-12}$ (Table I).

Advances in the cell and molecular biology of lipoprotein cell interactions have provided new insights into the mechanisms of atherosclerosis and much is now known about the regulation of plasma lipoprotein levels. The central role of the liver in these processes has been identified. The seminal work of Goldstein and Brown, ${ }^{13}$ which identified the LDL receptor pathway, provided the foundation for major advances in this field. This work has not only enabled the identification of genetic abnormalities underlying some of the primary hyperlipidaemias but also has led to an understanding of the mechanism of action of some lipid-modifying drugs and the logical development of new therapeutic agents.

Various consensus committees have reviewed recent developments and have furnished guidelines for optimal lipid and lipoprotein concentrations for the population as a whole in an attempt to reduce the burden of CHD. ${ }^{14,15}$ In addition, 
Table I Differences between changes in patients in treatment and control groups in angiographic trials of lipid-lowering therapy

\begin{tabular}{|c|c|c|c|c|}
\hline & $\begin{array}{c}L D L-C \\
\Delta \%\end{array}$ & $\begin{array}{c}H D L-C \\
\Delta \%\end{array}$ & $\begin{array}{l}\text { Prog } \\
\Delta \%\end{array}$ & $\begin{array}{l}\operatorname{Reg} \\
\Delta \%\end{array}$ \\
\hline NHLBI & & & & \\
\hline $\begin{array}{l}\text { Type } \text { II }^{8}(\mathrm{Ch}) \\
\text { CLAS }^{9}\end{array}$ & -20 & +6 & -17 & 0 \\
\hline $\begin{array}{l}\text { Co + NA } \\
\text { FATS }^{10}\end{array}$ & -36 & +35 & -22 & +14 \\
\hline $\begin{array}{c}\mathrm{L}+\mathrm{Co} \\
\mathrm{NA}+\mathrm{Co} \\
\mathrm{UCSF}^{11}\end{array}$ & $\begin{array}{l}-39 \\
-25\end{array}$ & $\begin{array}{l}+11 \\
+38\end{array}$ & $\begin{array}{l}-25 \\
-21\end{array}$ & $\begin{array}{l}+21 \\
+28\end{array}$ \\
\hline$\underset{\text { STARS }^{12}}{\mathrm{Co}+\mathrm{NA} \pm \mathrm{L}}$ & -28 & +28 & -21 & +20 \\
\hline $\begin{array}{l}\text { Diet } \\
\text { Diet }+ \text { Ch }\end{array}$ & $\begin{array}{l}-13 \\
-33\end{array}$ & $\begin{array}{r}0 \\
-\quad 4\end{array}$ & $\begin{array}{l}-31 \\
-34\end{array}$ & $\begin{array}{l}+34 \\
+29\end{array}$ \\
\hline
\end{tabular}

$\mathrm{Ch}=$ cholestyramine; $\mathrm{Co}=$ colestipol $; \mathrm{NA}=$ nicotinic acid $\mathrm{L}=$ lovastatin; NHLBI = National Heart Lung and Blood Institute; CLAS = Cholesterol Lowering Atherosclerosis Study; FATS = Familial Atherosclerosis Treatment Study; UCSF = University College San Francisco; STARS = St Thomas' Atherosclerosis Regression Study; Prog = progression; Reg = regression; LDL-C = LDL cholesterol; HDL-C $=$ HDL cholesterol.

Reproduced from Thompson, G.R. Progression and regression of coronary artery disease. Curr Opinion Lipidol 1992, 4, 263-267, with permission.

guidelines for the identification by screening and treatment of hyperlipidaemia have been published ${ }^{16,17}$ This review provides the current consensus of the views of the British Hyperlipidaemia Association, which consists of physicians and other health professionals involved in the management of lipid disorders. Hopefully general physicians, whether in hospital or the community, will find it of benefit in guiding their own practice.

\section{Screening for hyperlipidaemia}

Hyperlipidaemic individuals may be identified by plasma lipid measurements performed because they have clinically overt vascular disease. Others may have the clinical stigmata of hyperlipidaemia (premature arcus, xanthelasma, xanthomata) and many will be identified in screening programmes. The question of which individuals should have plasma lipid measurements performed has led to much debate within the profession. Certain countries such as the United States of America have instigated well-publicised cholesterol education programmes designed to ensure that every adult has their cholesterol measured by opportunistic screening. ${ }^{17}$ Although it is possible that other countries will adopt similar strategies in the future, a strategy of selectively screening only high risk individuals seems to prevail in the UK. The presence of hyperlipidaemia should be sought in individuals with clinically overt vascular disease; with the clinical stigmata of hyperlipidaemia; wite a strong family history of premature CHD 8 hyperlipidaemia; and those with other risk factoto for CHD such as hypertension, diabetes mellitu and obesity. It is recognized that not all individuals with significant hyperlipidaemia will be identified by these measures and more general screening may be appropriate on an opportunistic basis, as resources permit.

For general screening purposes a random, nonfasting plasma cholesterol measurement is appropriate. If this falls outside our previously published guidelines, ${ }^{18}$ a full lipid profile including plasma cholesterol, plasma triglyceride and HDL-cholesterol should be obtained following an overnight fast (12-14 hours). LDL-cholesterol can then be calculated using the Friedewald equation: ${ }^{19}$

LDL cholesterol $(\mathrm{mmol} / \mathrm{l})=$

Total cholesterol - HDL cholesterol $-\frac{\text { triglyceride }}{2.19}$ (applicable when total triglyceride $<4.5 \mathrm{mmol} / \mathrm{l}$ ).

Measurements are best performed in hospital chemical pathology departments. Care is required in venepuncture techniques as prolonged venous occlusion may increase cholesterol concentrations significantly. Posture also affects cholesterol levels with a significant fall on sitting and a further fall on lying down. It is recommended therefore that blood should be taken with minimal venous occlusion after the subject has been sitting for 10 minutes. Office-based machines employing dry chemistry 
technology have a role in screening as long as the instrument operator has received proper training and appropriate quality assurance is performed. However, it is inappropriate to make management decisions based solely on these tests.

In high risk groups it is advisable to perform a full fasting profile in the first instance as abnormalities of triglyceride and HDL cholesterol concentrations may otherwise be missed. Long-term plans should not be made without at least two measurements. An important practice point is that many intercurrent illnesses, including acute myocardial infarction and operative procedures, may depress plasma cholesterol levels and lead to falsely low readings. Some patients with hyperlipidaemia will require tests beyond the scope of routine laboratories. These are available in specialist lipid centres. ${ }^{20}$

\section{Diagnosis of hyperlipidaemia}

Once significant hyperlipidaemia has been identified it is important to diagnose the cause where possible. It is convenient to determine whether hyperlipidaemia is secondary to other conditions or is a primary abnormality. The principal secondary causes are shown in Table II. Diagnosis will require attention to clinical symptoms and signs and additional biochemical tests such as blood glucose, thyroid function, renal and liver function should be performed routinely.

If secondary causes are excluded it is presumed that a primary hyperlipidaemia is present. As knowledge of the metabolic and genetic abnormalities underlying these conditions has accumulated it has become possible to classify lipid disorders by genotype as opposed to laboratory phenotype. There is no doubt that lipoprotein phenotyping introduced in the early 1970s and adopted by the $\mathrm{WHO}^{21}$ gave a major impetus to the understanding of the hyperlipidaemias. However, this was a laboratory classification and has obvious drawbacks in the sense that it does not point to aetiology; for example, type IIa hyperlipidaemia (increased LDL cholesterol) can be the result of hypothyroidism or familial hypercholesterolaemia. For convenience the different lipoprotein phenotypes are shown in Table III which lists the more common primary hyperlipidaemias. Diagnosis requires consideration of the clinical symptoms and signs, family history of CHD and hyperlipidaemia, and laboratory assessment. This diagnostic process is important as primary disorders are associated with varying prognoses and differing treatments.

\section{Treatment}

The main aim of treatment in the majority of hyperlipidaemic patients is to reduce the risk of development of premature vascular disease (primary prevention) or the occurrence of further vascular events in those with clinical vascular disease (secondary prevention). Treatment is indicated in individuals with severe hypertriglyceridaemia primarily to prevent pancreatitis.

It cannot be overemphasized that treatment of hyperlipidaemia in the context of CHD prevention, either primary or secondary, should be part of the management of overall vascular risk. It is well established from prospective studies that risk factors interact to multiply the risk of CHD. It is

Table II Secondary hyperlipidaemias

\begin{tabular}{|c|c|}
\hline $\begin{array}{l}\text { Hormonal factors } \\
\text { Pregnancy } \\
\text { Diabetes mellitus } \\
\text { Hypothyroidism }\end{array}$ & $\begin{array}{l}\text { Liver disease } \\
\quad \text { Primary biliary cirrhosis } \\
\text { Extrahepatic biliary obstruction }\end{array}$ \\
\hline $\begin{array}{l}\text { Nutritional factors } \\
\text { Obesity } \\
\text { Anorexia nervosa } \\
\text { Alcohol abuse }\end{array}$ & $\begin{array}{l}\text { Iatrogenic } \\
\text { High dose thiazide diuretics* } \\
\beta \text {-Adrenergic receptor antagonists* } \\
\text { which lack } \alpha \text {-blocking effects, } \\
\text { intrinsic sympathetic activity } \\
\text { or vasodilator properties } \\
\text { Corticosteroids } \\
\text { Exogenous sex hormones }\end{array}$ \\
\hline $\begin{array}{l}\text { Renal dysfunction } \\
\text { Nephrotic syndrome } \\
\text { Chronic renal failure }\end{array}$ & Retinoids \\
\hline
\end{tabular}




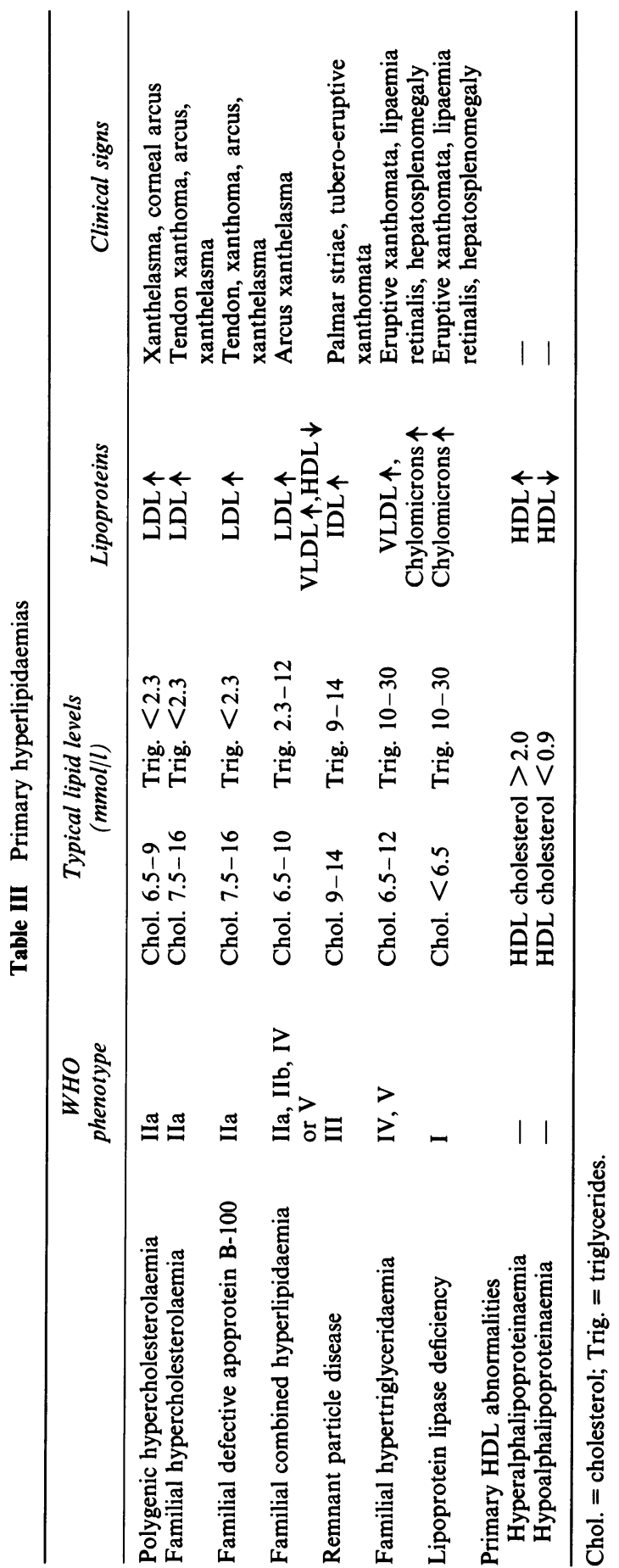

therefore mandatory not to regard a particular $\frac{0}{0}$ CHD risk factor in isolation and attention should § be given to the modification, where possible, of $\bar{z}$ other coexisting factors in each patient, particular- $\stackrel{\mathbb{Q}}{\complement}$ ly smoking and raised blood pressure.

The treatment of secondary hyperlipidaemia $\overrightarrow{\vec{F}}$ involves attention to the underlying cause (see $\stackrel{?}{?}$ Table II). However, in certain secondary causes of dyslipidaemia, particularly diabetes mellitus and $\frac{\bar{\sigma}}{\bar{\omega}}$. renal disease, significant lipid abnormalities may $\frac{\sigma}{\sigma}$ persist despite best endeavours at management of $\Omega$ the primary disorder. The risk of vascular disease is क high in these individuals and specific lipid-lowering $\overrightarrow{0}$ therapy may be indicated. A detailed discussion of the treatment of these patients is beyond the scope $\vec{\omega}$ of this article and the reader is referred to recent $\frac{\sigma}{\sigma}$ reviews of the topic. ${ }^{22,23}$

The goals of therapy in terms of plasma lipid and lipoprotein concentrations differ according to 8 whether primary or secondary prevention is the $\stackrel{\infty}{\rightarrow}$ objective. In the former context a total cholesterol $\overrightarrow{\dot{\omega}}$

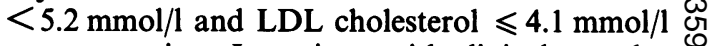
are appropriate. In patients with clinical vascular disease data from regression studies suggest that lower target values are necessary. It has been $\vec{z}$ suggested and is the view of the authors that in this important patient group the appropriate target $\overrightarrow{0}$ LDL cholesterol concentration should be $<3.8 \%$ $\mathrm{mmol} / \mathrm{l}^{17}$

\section{Lifestyle measures}

The cornerstones of treatment of hyperlipidaemia $\stackrel{\circ}{\varnothing}$ are nutritional and other lifestyle measures. These $\overrightarrow{\overrightarrow{0}}$ measures are often successful in individuals with $\frac{3}{3}$ moderate polygenic hyperlipidaemia where hypo- $\bar{F}$ lipidaemic drug therapy is seldom indicated. Lifestyle management should include advice on weight reduction in the obese, reduction of excessive $\underline{3}$. alcohol consumption, cessation of smoking and the encouragement of appropriate physical activity. In addition to the overall reduction of calories where $\delta$ appropriate, dietary intake of fat is reduced to no more than $30 \%$ of total calories. Dietary saturated 을 fat raises plasma cholesterol levels and potentiates the hypercholesterolaemic effect of dietary cholesterol. It is therefore important to reduce the $\bar{N}$ saturated fat content of the diet to less than $10 \%$ of $\sigma$ calories and the dietary intake of cholesterol below $300 \mathrm{mg} / \mathrm{day}^{16}$ (see Table IV).

Nutritional counselling should be individualized where possible and success is more likely where 0 counselling of the patient together with the patient's partner is undertaken. The provision of adequate $\stackrel{0}{+}$ dietetic support, particularly in the primary care $\square$ situation, remains a problem and the delivery of appropriate nutritional and lifestyle counselling will require optimum use of the limited profes- 
Table IV Cholesterol-lowering diet

\begin{tabular}{lc}
\hline & \% total calories \\
\hline Total fat & $\leqslant 30$ \\
$\quad$ Saturated fat & $\leqslant 10$ \\
$\quad$ Monosaturated fat & $\leqslant 10$ \\
Polyunsaturated fat & $\leqslant 10$ \\
Carbohydrate & $50-60$ \\
Protein & $10-20$ \\
Fibre & $35 \mathrm{~g} /$ day \\
Cholesterol & $<300 \mathrm{mg} /$ day \\
\hline
\end{tabular}

sional dietetic advice available. In primary care a suitably trained practice nurse may help fulfil this important role. The effectiveness of the delivery of nutritional advice and patient motivation will largely determine the success of treatment and obviate the inappropriate prescribing of hypolipidaemic drugs. Dietary measures should be pursued for at least 3-6 months before contemplating lipid-lowering drug therapy.

\section{Lipid-modifying drugs}

It is convenient to consider these agents under three main categories; drugs which lower plasma cholesterol alone, drugs which lower both plasma cholesterol and triglyceride, and drugs which lower plasma triglyceride alone. A detailed review of the mechanisms of action of hypolipidaemic agents has been published recently. ${ }^{24}$

\section{Drugs which lower plasma cholesterol alone}

\section{Anion-exchange resins}

These compounds which have been available for clinical use for over 20 years are non-absorbable basic anion-exchange resins which are hydrophilic but insoluble in water. After oral administration the resins bind to bile acids in the intestine preventing their reabsorption. In response more bile acids are synthesized by the liver from cholesterol, which is acquired from the plasma through increased LDL receptor activity. Cholesterol synthesis is also increased which partially offsets the cholesterollowering effect of resins. Nevertheless, in compliant patients these drugs can reduce LDL cholesterol levels by $20-30 \%$, with a slight increase in HDL cholesterol. Plasma triglycerides actually increase with resin therapy, however.

Currently two resins are available, cholestyramine and colestipol. They are in granular form and need to be mixed with water or other fluid prior to ingestion. Compliance can be a problem as the resins are not only inconvenient to take but produce gastrointestinal side effects of bloating, flatulence and constipation. These side effects can be ameliorated by a low dosage regimen of one sachet twice daily. Resins may interfere with the absorption of other drugs and there is a theoretical risk of malabsorption of fat-soluble vitamins but clinically this is rarely a problem. Folate levels should be monitored in pregnant women and in children.

\section{Probucol}

Probucol is a lipophilic bis-phenol compound structurally unrelated to the other lipid-lowering drugs. It produces moderate reductions in plasma cholesterol $(\approx 15 \%)$ and its maximal effect may take up to 3 months to occur. Probucol reduces HDL cholesterol as well as LDL cholesterol and for this reason has not been considered as first-line therapy. However, clinically, probucol is associated with mobilization of tissue cholesterol from skin and tendon xanthomata.

There is increasing interest in the role of oxidized LDL in atherogenesis. Probucol has antioxidant effects which in vitro and in animal studies inhibit LDL oxidation and atherogenesis. ${ }^{25}$ However, there is as yet no evidence in man of an antiatherogenic effect of the drug.

Probucol is generally well tolerated. Prolongation of the Q-T interval on the electrocardiogram has been described but the clinical significance of this is unclear. The drug accumulates in adipose tissue and may persist for many weeks after the last dose. For this reason the drug should be stopped in women at least 6 months prior to attempted conception.

\section{Drugs which lower plasma cholesterol and triglyceride}

\section{Fibric acid derivatives}

Several fibrates are available for clinical use in Britain: bezafibrate, ciprofibrate, fenofibrate and gemfibrozil. On the whole these agents are more effective than the parent compound, clofibrate, which is now obsolete owing to the associated increased risk of gallstones. The exact mode(s) of action of the fibrates remain to be determined but the main effect is to stimulate clearance of triglyceride-rich lipoproteins.

The major effect of fibrate drugs is to reduce plasma triglyceride levels $(\approx 50 \%)$. HDL cholesterol levels increase $(\approx 15-20 \%)$ with therapy but effects on plasma cholesterol and LDL cholesterol vary depending on the type of hyperlipidaemia. In patients with isolated hyper- 
cholesterolaemia or mixed hyperlipidaemia fibrate therapy is associated with reductions of plasma LDL cholesterol of 10-25\%. On the other hand, in patients with isolated hypertriglyceridaemia (type IV), where LDL concentrations tend to be low, LDL cholesterol may increase with fibrate therapy.

Apart from minor gastrointestinal symptoms the fibrates are generally well tolerated and more serious side effects are rare. Occasionally, abnormalities of liver function occur and myopathy has been reported especially in subjects with impaired renal function. The fibrates interact with anticoagulants increasing anticoagulant activity.

The long-term safety of fibrates has been questioned following the findings of the WHO primary prevention trial of cholesterol-lowering in the 1970s which used clofibrate. ${ }^{26}$ The mortality rate from non-cardiac causes was increased in the clofibrate-treated group due to an increased incidence of malignancy and gallstone related disorders, including cholecystectomy. Such effects were not observed in the Helsinki Heart Study where the drug used was gemfibrozil. ${ }^{27}$

\section{Nicotinic acid}

In pharmacological doses nicotinic acid (3-6 g/ day) lowers plasma cholesterol and plasma triglyceride and increases HDL cholesterol. The mechanism of action of the drug is not fully understood. It is unlikely that the welldemonstrated inhibition of the breakdown of adipose tissue triglyceride fully explains its effect.

Nicotinic acid is poorly tolerated because of flushing and gastrointestinal symptoms; these can be overcome to a certain extent by starting the drug in low dosage. Tachyphylaxis to the flush develops but is lost if a dose is missed. The flush appears to be prostaglandin mediated as it is partly blocked by aspirin. Other side effects include a pruritic rash and hyperpigmentation. Nicotinic acid may exacerbate gout and glucose intolerance and produce abnormalities of liver function. Two nicotinic acid analogues, acipimox and nicofuranole, Bradilan, are available for clinical use in the UK. These agents are generally better tolerated than nicotinic acid, both in terms of symptoms and metabolic side effects, and acipimox does not impair glucose tolerance. The analogues are not as effective in modifying plasma lipid levels as nicotinic acid itself. ${ }^{28}$

\section{HMG-CoA reductase inhibitors}

The introduction of this new, exciting class of drugs into clinical practice represents a major advance in the therapy of hyperlipidaemia. ${ }^{29}$ There are currently two members of this class available in the UK, pravastatin and simvastatin. These agents are specific competitive inhibitors of the microsomal enzyme HMG-CoA reductase which catalyses the conversion of HMG-CoA to mevalonate, a major rate-determining step in cholesterol synthesis. They are very potent inhibitors of the enzyme with $K_{1}$ values ranging from 0.2 to $2.2 \times 10^{-9} \mathrm{M}$ compared to the $K_{\mathrm{m}}$ of the natural substrate which is $4 \times 10^{-6} \mathrm{M}$. The liver is the major organ for catabolism of LDL and the activity of specific hepatic receptors which bind and take up LDL largely determines plasma LDL concentrations. The inhibition of hepatic cholesterol synthesis by these drugs stimulates the expression of LDL receptors resulting in increased uptake of $L D L$ and a reduction in its plasma concentration. LDL production is also decreased. Very low density lipoprotein (VLDL) is catabolised by the enzyme lipoprotein lipase resulting in VLDL remnants which can either be taken up by hepatic LDL receptors or further catabolised to LDL. Increased LDL receptor activity as a result of HMG-CoA reductase inhibition will therefore result in increased direct hepatic uptake of VLDL remnants and consequent decreased conversion to LDL.

As expected from their mode of action, these drugs have a major impact on plasma cholesterol levels through the reduction of LDL cholesterol. This effect is dose-dependent and maximal after $\$$ weeks of therapy. Reductions of $30-40 \%$ in plasma LDL cholesterol are commonly achieved음 Modest reductions in plasma triglycerides $(10-20 \%)$ are also observed together with a small increase in HDL. The reduction in LDL cholesterol is paralleled by a reduction in apoprotein $\mathrm{B}$, the major protein component of LDL.

The HMG-CoA reductase inhibitors are convenient to take as once-daily dosage and are generally well tolerated with few adverse effects. Unlike triparanol, an inhibitor of cholesterol synthesis on trial in the 1960s, there is no evidence of any deleterious effects of the HMG-CoA inhibitors on the lens. Rarely, elevated liver transaminases are observed but these abnormalities are rapidly reversible when the drugs are discontinued. Potentially the most important side effect is myositis with marked elevation of plasma creatine kinase. Most of the reported cases have been in patients taking the drugs with other agents particularly cyclosporine, nicotinic acid and gemfibrozil or in patients with significant hepatic disease. The frequency of myositis is very rare.

There is no evidence of clinically significant effects of the drugs on other products of the cholesterol synthetic pathway such as steroid hormones, ubiquinones and dolichols. 


\section{Drugs which lower plasma triglyceride alone}

\section{Omega-3 fatty acids}

Omega-3 fatty acids when taken in large amounts appear to reduce hepatic VLDL synthesis. Maxepa (a preparation containing eicosapentaenoic acid and decosahexaenoic acid) is licenced in the UK and is useful for the treatment of severe hypertriglyceridaemia. In the recommended dosage $(10 \mathrm{~g} /$ day) Maxepa does not reduce plasma cholesterol concentrations and in more modest hypertriglyceridaemia LDL concentrations may even increase with treatment.

\section{When to use drugs and which drugs to use}

Lipid-lowering drug therapy should not be undertaken lightly as therapy is usually lifelong and its risk/benefit ratio should be carefully considered. The important clinical question is does the anticipated benefit of drug therapy in terms of reduction of CHD risk outweigh the imposition of long-term drug therapy with the potential for unpredicted adverse effects? Drug therapy should be reserved for those patients at high risk where lifestyle measures have failed to result in acceptable plasma lipid levels. In general terms, those patients with clinical vascular disease, those with severe hyperlipidaemias (familial hypercholesterolaemia, familial combined hyperlipidaemia and remnant particle disease) and those with other major risk factors are more likely to require drug therapy. A guide to priorities for therapy is given in Table V.
The choice of hypolipidaemic drug will depend mainly upon the nature and severity of the lipid disorder to be treated, as shown in Table VI. For isolated moderate hypercholesterolaemia first line agents would be the anion exchange resins. In this situation relatively small doses of the resins will be effective. Fibrates can be tried if patients are intolerant of resins. In severe hypercholesterolaemia due to increased LDL cholesterol, as seen in familial hypercholesterolaemia, the HMG-CoA reductase inhibitors are effective first line agents. Despite their excellent efficacy in reducing LDL cholesterol $(\approx 30-40 \%)$ the LDL concentration may not reach acceptable levels because of the very high pretreatment value. In this situation concomitant low dose resin therapy will have additional benefit.

In children and women of child-bearing age resins are very useful agents because they are not absorbed. Women treated with other lipidlowering drugs should be advised to stop the medication prior to conception. More information is required on pharmacological therapy of children with heterozygous familial hypercholesterolaemia. Until more is known, resins remain the drugs of choice in this situation.

In the patient with raised cholesterol and triglycerides where the predominant abnormality is hypercholesterolaemia, the fibrates can be used as first line agents. In some patients cholesterol may remain high despite a satisfactory reduction in plasma triglyceride. The addition of low dose resin therapy is a useful option here. The HMG-CoA reductase inhibitors are also useful in these patients as single therapy. However, plasma triglycerides

Table V Priorities and action limits for lipid-lowering drug therapy in diet-resistant subjects*

\begin{tabular}{llcc}
\hline Priority & Subject category & $\begin{array}{c}\text { Total cholesterol } \\
(\text { mmol/l) }\end{array}$ & $\begin{array}{c}\text { LDL cholesterol } \\
(\text { mmol/l) }\end{array}$ \\
\hline First & $\begin{array}{l}\text { Patients with existing CHD, } \\
\text { or post-CABG, angioplasty } \\
\text { or cardiac transplant }\end{array}$ & $>5.2$ & $>3.4$ \\
Second & $\begin{array}{l}\text { Patients with multiple risk } \\
\text { factors or genetically determined } \\
\text { hyperlipidaemia, e.g. FH }\end{array}$ & $>6.5$ & $>5.0$ \\
Third & $\begin{array}{l}\text { Males with asymptomatic } \\
\text { hypercholesterolaemia }\end{array}$ & $>7.8$ & $>6.0$ \\
Fourth & $\begin{array}{l}\text { Postmenopausal females } \\
\text { with asymptomatic } \\
\text { hypercholesterolaemia }\end{array}$ & $\begin{array}{c}>7.8 \\
\text { and HDL ratio } \\
<0.2^{*}\end{array}$ & $>6.0$ \\
\hline
\end{tabular}

*Aim of cholesterol lowering should be an LDL cholesterol $<3.4 \mathrm{mmol} / 1$ in the presence of CHD and $<4.1 \mathrm{mmol} / 1$ in the absence of CHD. 
Table VI Drug therapy of hyperlipidaemia

\begin{tabular}{lclll}
\hline $\begin{array}{l}\text { Lipid } \\
\text { abnormality }\end{array}$ & $\begin{array}{c}\text { LDL } \\
\text { cholesterol }\end{array}$ & $\begin{array}{l}\text { Degree of } \\
\text { hyperlipidaemia }\end{array}$ & 1st choice & $\begin{array}{l}\text { Drug regimen } \\
\text { 2nd choice }\end{array}$ \\
\hline $\begin{array}{l}\text { Type IIa } \\
\text { Cholesterol } \uparrow\end{array}$ & $\uparrow$ & $\begin{array}{l}\text { Moderate } \\
\text { Severe }\end{array}$ & $\begin{array}{l}\text { Resin } \\
\text { Statin } \\
\text { Resin + statin }\end{array}$ & $\begin{array}{l}\text { Fibrate } \\
\text { Probucol }\end{array}$ \\
$\begin{array}{l}\text { Type IIb } \\
\text { Cholesterol } \uparrow \\
\text { Triglyceride } \uparrow\end{array}$ & $\uparrow$ & Moderate & Fibrate & NA \\
$\begin{array}{l}\text { Type III } \\
\text { Cholesterol } \uparrow \\
\text { Triglyceride } \uparrow\end{array}$ & N or $\downarrow$ & Usually severe & Fibrate & Statin \\
$\begin{array}{l}\text { Type IV } \\
\text { Triglyceride } \uparrow \\
\begin{array}{l}\text { Cholesterol } \mathrm{N} \\
\text { or } \uparrow\end{array}\end{array}$ & $\mathrm{N}$ & Moderate & Fesin + fibrate & \\
$\begin{array}{l}\text { Type V } \\
\text { Triglyceride } \uparrow \\
\text { Cholesterol } \uparrow\end{array}$ & or statin & Fibrate & NA \\
\hline
\end{tabular}

Severe hyperlipidaemia is defined as a serum cholesterol $>7.8$ or fasting triglyceride $>4.5 \mathrm{mmol} / \mathrm{l}$, especially if they occur together or are accompanied by an HDL cholesterol $<1 \mathrm{mmol} / \mathrm{l}$. Resin $=$ cholestyramine or colestipol; Fibrate = bezafibrate, ciprofibrate, fenofibrate, gemfibrozil; Statin (HMG-CoA reductase inhibitor) = pravastatin, simvastatin; NA (nicotinic acid or derivative) $=$ acipimox; $N=$ normal.

may remain high. The addition of a fibrate or nicotinic acid to a statin to reduce plasma triglycerides in these patients cannot be generally recommended because of the potential for adverse reactions, particularly myositis.

Fibrates remain the treatment of first choice in remnant particle disease (type III). In addition, there are favourable reports of the use of HMGCoA reductase inhibitors in this condition. Resins aggravate the hypertriglyceridaemia and are contraindicated.

Pharmacological treatment of isolated moderate hypertriglyceridaemia remains controversial. However, some patient groups may be considered for drug therapy if lifestyle measures are ineffective, including patients with known CHD, familial combined hyperlipidaemia, familial hypertriglyceridaemia, a family history of CHD, remnant particle disease, diabetes mellitus and a low HDLcholesterol. ${ }^{30}$ Fibrates and nicotinic acid or its derivatives are the drugs of choice for isolated hypertriglyceridaemia. LDL cholesterol tends to be low in these subjects and may rise with fibrate therapy in some individuals. For this reason, LDL concentrations should be monitored.
Fibrates are the first line treatment for severe hypertriglyceridaemia with chylomicronaemia. Omega-3 fatty acids may also be useful in this situation and can be used in conjunction with fibrates. Nicotinic acid or its derivatives can also be usefully added to fibrate therapy.

In chylomicronaemia of childhood due to lipoprotein lipase deficiency or apoprotein C-II deficiency, no pharmacological treatment is available. However, the very low fat diet necessary in these individuals may be supplemented by medium chain triglycerides to improve tolerability.

\section{Monitoring drug therapy}

The response to lipid-lowering drug therapy is not always predictable and plasma lipid and lipoprotein concentrations should be monitored to ensure adequate response. If one fibrate is ineffective another member of the fibrate class can be tried. The response to HMG-CoA reductase inhibitors is more predictable and the majority of patients will show the expected response. Failure to respond to resins usually indicates poor compliance. 
Patients should be questioned with regard to possible side effects of the drugs and intermittent measurements of liver function tests are indicated during therapy with fibrates and HMG-CoA reductase inhibitors. If patients develop muscle pain then measurement of creatine kinase is indicated. Myositis is more likely to occur when HMG-CoA reductase inhibitors are combined with fibrates or nicotinic acid and when other drugs are used concurrently such as cyclosporine. Very careful monitoring is required in these patients. Patients taking nicotinic acid need screening for potential metabolic effects including liver function tests, uric acid and plasma glucose. Ophthalmological surveillance is also required in patients taking nicotinic acid as a reversible macular oedema may occur rarely. Initial concerns about cataracts with the HMG-CoA reductase inhibitors have not materialized and there is no need for routine ophthalmological surveillance.

\section{Non-pharmacological therapy}

\section{Surgical procedures}

Partial ileal bypass ${ }^{31}$ involving the terminal one third of the ileum has been performed in the past in heterozygous familial hypercholesterolaemic individuals intolerant of resin therapy. Reductions in LDL cholesterol of about $30 \%$ have been achieved. Postoperative diarrhoea, mild steatorrhoea and the need for vitamin $B_{12}$ replacement are disadvantages of this procedure. The advent of the HMG-CoA reductase inhibitors means that few patients will now be candidates for this operation despite recent evidence of its effectiveness in decreasing coronary mortality and morbidity. ${ }^{32}$

In homozygous familial hypercholesterolaemia, liver transplantation is the most definitive treatment providing a source of LDL receptor activity but at the cost of life-long immunosuppression. A combined heart/liver transplant was originally performed in 1984 in a 7-year-old patient. The cholesterol fell from a preoperative concentration of $25 \mathrm{mmol} / 1$ to $7 \mathrm{mmol} / \mathrm{l}^{33}$

\section{Plasma exchange and related techniques}

Plasma exchange was first used in 1974 for the treatment of homozygous familial hypercholesterolaemia. ${ }^{34}$ Regular exchanges (weekly or biweekly) led to regression of xanthomata and slowing of progression of atherosclerosis. Recently more selective procedures have been developed including LDL apheresis with disposable affinity columns. These columns remove apoprotein B containing lipoproteins including Lp(a), but HDL is conserved. ${ }^{35}$ An alternative technique involves the precipitation of LDL with heparin - the Heparin Extracorporal LDL Precipitation (HELP) system. $^{36}$

\section{Controversial issues}

\section{Overall mortality}

It is generally accepted that primary prevention trials of cholesterol-lowering reduce the risk of non-fatal and fatal CHD. ${ }^{37}$ However, concern has been expressed in some quarters that these trials have failed to show a reduction in total mortality. Further, the potential adverse effects of lipidlowering therapy in increasing non-cardiac deaths has been emphasized by some authors. ${ }^{38,39}$ It should be remembered that these trials have not had the statistical power to answer the question as to whether or not cholesterol-lowering alters total mortality. It is highly unlikely that a trial with such statistical power will ever be carried out because of the cost. For the time being the apparent increase in non-cardiovascular mortality observed in some drug trials remains unexplained and needs to be investigated further before its clinical significance can be assessed. The variety of drugs used, some of them now obsolete, the very wide range of causes of non-CHD death and the lack of increase in the latter when cholesterol was lowered in diet trials renders a single causal mechanism most unlikely. In the meantime responsible use of cholesterollowering drugs in diet-resistant patients with CHD or at high risk of developing CHD remains good clinical practice.

\section{The elderly}

The gradient of risk between plasma cholesterol levels and CHD risk is less steep in the elderly. However, the number of CHD events is much greater and the risk attributable to cholesterol is therefore high. Currently there is a view that primary prevention with hypolipidaemic agents should not be undertaken after the age of 65 . Trials beginning in the United States of lipid-lowering in the elderly will help to clarify the position with regard to this increasing sector of the population.

\section{Women}

Premenopausal women are at lower risk of CHD than men and the major trials of lipid-lowering therapy have been confined to men. More research is needed in more clearly defining individual risk in women, particularly as caution is required with the prescription of most hypolipidaemic drugs if pregnancy is likely.

In postmenopausal women the risk of CHD 
increases steeply, possibly related to increasing plasma LDL cholesterol levels. Changes in plasma lipoprotein concentrations are ameliorated by hormone replacement therapy. More information is required on the effects of combined hormone therapy (progestogen and oestrogen) on vascular risk and on whether the progestogen, necessary for the prevention of endometrial hyperplasia, reduces the benefit conferred by the oestrogen.

\section{Children}

Children from families carrying the gene for familial hypercholesterolaemia (FH) should be screened for the presence of hypercholesterolaemia at an early age. It is generally accepted that a low-fat, low-cholesterol diet can be prescribed after the age of 5 years. However, more information is needed on the safety of systemically active hypolipidaemic drug therapy in children. In FH families where the clinical onset of CHD is early it may be necessary to prescribe drug therapy in children but most physicians would wait until after puberty.

\section{Summary}

There is considerable evidence to suggest that the identification and treatment of dyslipidaemia will

\section{References}

1. Martin, M.J., Hulley, S.B., Browner, W.S., Kuller, L.H. \& Wentworth, D. Serum cholesterol, blood pressure and mortality: implications from a cohort of 361,662 men. Lancet 1986, ii: $933-936$

2. Chen, Z., Peto, R., Collins, R., MacMahon, S., Lu, J. \& Li, W. Serum cholesterol concentration and coronary heart disease in population with low cholesterol concentrations. $\mathrm{Br}$ Med J 1991, 303: 276-282.

3. Kannel, W.B., Gordon, T. \& Castelli, W.P. Role of lipid and lipoprotein fractions in assessing atherogenesis. The Framingham Study. Progr Lipid Res 1981, 20: 339-348.

4. Castelli, W.P., Garrison, R.J., Wilson, P.W.F., Abbott, R.D., Kalousdian, S. \& Kennel, W.B. Incidence of coronary heart disease and lipoprotein cholesterol levels. JAMA 1986, 256: $2835-2838$.

5. Hulley, S.B. \& Avins, A.L. Asymptomatic hypertriglyceridaemia. Br Med J 1992, 304: 394-396.

6. Rossouw, J.E. \& Rifkind, B.M. Does lowering serum cholesterol levels lower coronary heart disease risk? In: LaRosa, J.C. (ed) Endocrinology and Metabolism Clinics of North America. Lipid Disorders, Vol. 19, no. 2. W.B. Saunders, Philadelphia, 1990, pp. 279-297.

7. Rossouw, J.E., Lewis, B. \& Rifkind, B.M. The value of lowering cholesterol after myocardial infarction. $N$ Engl $J$ Med 1990, 323: 1112-1119.

8. Levy, R.I., Brensike, J.F., Epstein, S.E. et al. The influence of changes in lipid values induced by cholestyramine and diet on progression of coronary artery disease: results of the NHLBI type II coronary intervention study. Circulation 1984, 69: 325-337. reduce the risk of premature CHD, i.e. before the age of 65. Diagnosis of the cause of raised plasma lipid levels will enable appropriate decisions to be taken with regard to management. The cornerstone of treatment is nutritional counselling and attention to other major risk factors for CHD, particularly smoking and hypertension. For a small percentage of patients with severe hyperlipidaemia drug therapy is indicated. Appropriate drug choices need to be made based on the particular lipid abnormality to be treated. In general those patients with clinical vascular disease are treated more aggressively than those where the aim is primary prevention.

More research is needed to determine individual risk more precisely and to allow proper targeting of therapy. Genetic factors, qualitative changes in lipoproteins, lipoprotein (a), fibrinogen, and other coagulation and thrombotic factors are likely to be important in individual risk assessment.

There is no doubt that more information is needed from prospective studies of lipid-lowering therapy in terms of risk benefit for affected individuals. Hopefully the major studies currently underway will fill some of the gaps in our knowledge. Until then aggressive therapy with drugs should be reserved for those at highest risk where the benefit is likely to be greatest.

9. Blankenhorn, D.H., Nessim, S.A., Johnson, R.L., Sanmarco, M.E., Azen, S.P. \& Cashin-Hemphill, L. Beneficial effects of combined colestipol-niacin therapy on coronary atherosclerosis and coronary venous bypass grafts. JAMA 1987, 257 3233-3240.

10. Brown, G., Albers, J.J. \& Fisher, L.D. Regression of coronary artery disease as a result of intensive lipid lowering therapy in men with high levels of apolipoprotein B. $N$ Engl $J$ Med 1990, 323: 1289-1298.

11. Kane, J.P., Malloy, M.J., Ports, T.A., Phillips, N.R., Diehl, J.C. \& Havel, R.J. Regression of coronary atherosclerosis during treatment of familial hypercholesterolaemia with combined drug regimens. JAMA 1990, 264: 3007-3012.

12. Watts, G.F., Lewis, B., Brunt, J.N.H. et al. Effects on coronary artery disease of lipid-lowering diet, or diet plus cholestyramine, in the St. Thomas' Atherosclerosis Regression Study (STARS). Lancet 1992, 339: 563-569.

13. Brown, M.S. \& Goldstein, J.L. Receptor-mediated control of cholesterol metabolism. Science 1986, 191: 150-154.

14. Consensus Conference. Lowering blood cholesterol to prevent heart disease. JAMA 1985, 253: 2080-2086.

15. Study Group of the European Atherosclerosis Society. Strategies for the prevention of coronary heart disease, a policy statement of the European Atherosclerosis Society. Eur Heart J 1987, 8: 77-88.

16. Study Group of the European Atherosclerosis Society. The recognition and management of hyperlipidaemia in adults: a policy statement of the European Atherosclerosis Society. Eur Heart J 1988, 9: 571-600. 
17. Report of the National Cholesterol Education Program Expert Panel on Detection, Evaluation and Treatment of High Blood Cholesterol in Adults. Arch Intern Med 1988, 148: 36-69.

18. Shepherd, J., Betteridge, D.J., Durrington, P.N. et al. Strategies for reducing coronary heart disease and desirable limits for blood lipid concentrations: guidelines of the British Hyperlipidaemia Association. Br Med J 1987, 295: 1245-1246.

19. Friedewald, W.T., Levy, R.I. \& Fredrickson, D.S. Estimation of the concentration of low density lipoprotein cholesterol in plasma, without use of the preparative ultracentrifuge. Clin Chem 1972, 18: 499-502.

20. Laker, M.F., Reckless, J.P.D., Betteridge, D.J. et al. Laboratory facilities for investigating lipid disorders in the United Kingdom: results of the British Hyperlipidaemia Association Survey. J Clin Pathol 1992, 45: 102-105.

21. Beaumont, J.L., Carlson, L.A., Cooper, G.R., Fejfar, Z., Fredrickson, D.S. \& Strasser, T. Classification of hyperlipidaemias and hyperlipoproteinaemias. Bull World Health Organisation 1970, 43: 891-915.

22. Betteridge, D.J. Lipids, diabetes and vascular disease: the time to act. Diabet Med 1989, 6: 195-218.

23. Short, C.D. \& Durrington, P.N. Hyperlipidaemia and renal disease. In: Betteridge, D.J. (ed) Clinical Endocrinology and Metabolism. Lipid and Lipoprotein Disorders, Vol. 4, no. 4, Bailliere Tindall, London, 1990, pp. 777-806.

24. O'Connor, P., Feely, J. \& Shepherd, J. Lipid lowering drugs. Br Med J 1990, 300, 667-672.

25. Kita, T., Nagano, Y., Yokode, M. et al. Probucol prevents the progession of atherosclerosis in Watanabe heritable hyperlipidaemic rabbit, an animal model for familial hypercholesterolaemia. Proc Natl Acad Sci USA 1987, 84: 5928-5231.

26. Report from the Committee of Principal Investigators. A cooperative trial in the primary prevention of ischaemic heart disease using clofibrate. Br Heart J 1978, 40: 1069-1118.

27. Frick, M.H., Elo, O., Haapa, K. et al. Helsinki Heart Study: primary prevention trial with gemfibrozil in middle-aged men with dyslipidaemia. $N$ Engl J Med 1987, 317: 1237-1245.

28. O'Kane, M.J., Trinick, T.R., Tynan, M.B., Trimble, E.R. \& Nicholls, D.P. A comparison of acipimox and nicotonic acid in type 2b hyperlipidaemia. Br J Clin Pharmac 1992, 33: 451-453.
29. Grundy, S.M. HMG-CoA reductase inhibitors for treatment of hypercholesterolaemia. $N$ Engl J Med 1988, 319: 24-33.

30. Assmann, G., Betteridge, D.J., Gotto, A.M. \& Stainer, G. Management of hypertriglyceridaemic patients. Treatment classifications and goals. Am J Cardiol 1991, 68: 30A-34A.

31. Buchwald, $H$. Lowering of cholesterol absorption and blood levels by ileal exclusion. Circulation 1964, 29: 713-720.

32. Buchwald, H., Varco, R.L., Matts, J.P. et al. Effect of partial ileal bypass surgery on mortality and morbidity from coronary heart disease in patients with hypercholesterolaemia. Report of the Program on the Surgical Control of the Hyperlipidaemias (POSCH). N Engl J Med 1990, 323: 946-955.

33. Starzl, T.E., Bilheimer, D.W., Bahnson, H.T. et al. Heart-liver transplantation in a patient with familial hypercholesterolaemia. Lancet 1984, i: 1382-1383.

34. Thompson, G.R., Lowenthal, R. \& Myant, N.B. Plasma exchange in the management of homozygous familial hypercholesterolaemia. Lancet 1975, i: 1208-1211.

35. Yokoyama, S., Hayashi, R., Santani, M. \& Yamamoto, A Selective removal of low density lipoprotein by plasmapheresis in familial hypercholesterolaemia. Arteriosclerosis 1985, 5: 613-622.

36. Fuchs, C., Windisch, M., Wieland, H. et al. Selective continuous extracorporeal elimination of low density lipoproteins from plasma by heparin precipitation without cations. In: Plasma Separation and Plasma Fractionation. Karger, Basel, 1983, pp. 272-280.

37. Holme, I. An analysis of randomized trials evaluating the effect of cholesterol reduction on total mortality and coronary heart disease incidence. Circulation 1990, 82: 1916-1924.

38. Muldoon, M.F., Manuck, S.B. \& Matthews, K.A. Lowering cholesterol concentrations and mortality: a quantitative review of primary prevention trials. $\mathrm{Br}$ Med $J$ 1990, 301: 309-314.

39. Smith, G.D. \& Pekkanen, J. Should there be a moratorium on the use of cholesterol lowering drugs? Br Med J 1992, 304: 431-434. 